\title{
Congenital heart disease diagnosed with echocardiogram in newborns with asymptomatic cardiac murmurs: a systematic review
}

\author{
Shin Ae Yoon ${ }^{1}$, Woi Hyun Hong ${ }^{2^{*}}$ (i) and Hwa Jin $\mathrm{Cho}^{3}$
}

\begin{abstract}
Background: More than 50\% of newborns with congenital heart disease (CHD) are unrecognized at birth; however, the use of echocardiogram (Echo) for diagnosing CHD in newborns with asymptomatic, non-syndromic cardiac murmurs (ANCM), has not been systematically reviewed yet. We aimed to identify the incidence of CHD diagnosed with Echo and systematically review whether Echo should be recommended in this patient group.

Methods: The methodology utilized in this systematic review adhered to the Preferred Reporting Items for Systematic Reviews and Meta-Analyses framework. Using the MEDLINE, EMBASE, Web of Science, and Cochrane Library databases, we performed a systematic review of publications reporting CHD diagnosed with Echo in newborns with cardiac murmurs. The quality of the included studies was evaluated using the Study Quality Assessment Tools developed by the National Institutes of Health.

Results: Of the 630 studies screened, six cohort studies, four cross-sectional studies, and two case reports were included in this review. The incidence of cardiac murmurs ranged from 0.6-8.6\%. Among the 1928 newborns with ANCM, 719 (37.3\%) were diagnosed with Echo as having CHD, and ventricular septal defect was the most common congenital malformation. More than 50\% of the newborns showed moderate CHD necessitating outpatient cardiology follow-up, and $2.5 \%$ had severe CHD requiring immediate interventions, such as cardiac catheterization and heart surgery.

Conclusions: In this systematic review, a high incidence of CHD in newborns with ANCM was detected using Echo. This indicates that the use of Echo for diagnosing CHD in healthy newborns with cardiac murmurs could be helpful in earlier detection of CHD, thereby improving clinical outcomes for newborns with severe CHD.
\end{abstract}

Keywords: Cardiac assessment, Asymptomatic non-syndromic cardiac murmurs, Echocardiogram, Newborns, Congenital heart disease

\footnotetext{
* Correspondence: hong.medric@gmail.com

${ }^{2}$ College of Medicine, Medical Research Information Center, Chungbuk

National University, (28644) 1 Chungdae-ro, Seowon-gu, Cheongju-si,

Chungcheongbuk-do, South Korea

Full list of author information is available at the end of the article
}

(c) The Author(s). 2020 Open Access This article is licensed under a Creative Commons Attribution 4.0 International License, which permits use, sharing, adaptation, distribution and reproduction in any medium or format, as long as you give appropriate credit to the original author(s) and the source, provide a link to the Creative Commons licence, and indicate if changes were made. The images or other third party material in this article are included in the article's Creative Commons licence, unless indicated otherwise in a credit line to the material. If material is not included in the article's Creative Commons licence and your intended use is not permitted by statutory regulation or exceeds the permitted use, you will need to obtain permission directly from the copyright holder. To view a copy of this licence, visit http://creativecommons.org/licenses/by/4.0/ The Creative Commons Public Domain Dedication waiver (http://creativecommons.org/publicdomain/zero/1.0/) applies to the data made available in this article, unless otherwise stated in a credit line to the data. 


\section{Background}

Congenital heart disease (CHD) is a leading cause of death in newborns [1-3]. CHD prevalence in newborns has increased globally, especially in Asia, from 0.6 per 1000 live births to 9.410 per 1000 live births, according to several recent reports [4-7]. Despite antenatal screening processes using fetal echocardiogram (Echo), more than $50 \%$ of newborns with CHD are unrecognized at birth [8-10]. As undiagnosed CHD can lead to lifethreatening cardiovascular collapse and cardiac arrest, which are the primary causes of death in infants, screening newborns' cardiac health is vital $[8,11]$.

Cardiac assessments, including physical examinations, have been performed for newborns after birth; however, the use of Echo for diagnosing CHD, especially in newborns with asymptomatic, non-syndromic cardiac murmurs (ANCM), has been a subject of debate [12-14]. Echo, which pediatricians use to evaluate heart function, uses sound waves to produce pictures of the movement of different parts of the heart; thus, it has become the gold standard for diagnosis of CHD in pediatric patients with cardiac murmurs and its use has expanded with advances in technology [15-18]. Almost all pediatricians agree with performing Echo for newborns with cardiorespiratory symptoms, such as cyanosis and tachypnea; chromosome abnormalities, including Down syndrome; or other non-cardiac anomalies to rule out CHD [19, 20]. The appropriate criteria for the use of Echo in children and adolescents with cardiac murmurs are well established [21-23]; however, guidelines for the use of Echo in newborns with ANCM have not yet been reported. Cardiac murmurs are commonly found in newborns and are one of the major signs of potential CHD. Moreover, pediatric cardiac murmur is the primary reason for referral and further evaluations. Therefore, CHD detection in newborns with ANCM is necessary for early diagnosis and timely treatment.

Recently, it has become easy to implement Echo in neonatal care. Previous studies reported variable CHD incidence in newborns with ANCM [24-26]; however, there is no consensus on the use of Echo for early detection of CHD in newborns with ANCM. In this systematic review, we aimed to identify the incidence of CHD diagnosed with Echo and determine whether Echo should be used in the proper management of CHD in newborns with ANCM.

\section{Methods}

This systematic review selected CHD evaluated the usefulness of Echo in identifying CHD in newborn babies with ANCM. No systematic review has yet reported on the incidence of CHD or echocardiographic outcomes in newborns with ANCM.

\section{Inclusion and exclusion criteria}

The inclusion criteria for published studies in this review were based on the PICOT (population/patient, intervention, comparison, outcome, and time) study design questions according to the Preferred Reporting Items for Systematic Reviews and Meta-Analyses (PRISMA) guidelines [27]. Studies were included if they met the following criteria:

1. included newborns with asymptomatic cardiac murmurs diagnosed by health professionals using echocardiogram,

2. CHD was determined based on initial screening and additional screening methods, such as physical exam, family history, and echocardiogram performed by physicians,

3. study designs included all kinds of clinical trials, such as prospective and retrospective cohort studies, observational studies, case control studies, and case reports, that explored the differential diagnosis from ANCM to CHD based on first and second screenings in full term newborns.

The following studies were excluded: animal studies; reviews, comments, editorials, conference abstracts or papers, letters, and notes; studies without a specified number of cases, that did not perform echocardiogram, or that included symptomatic patients; cases of preterm newborn babies or babies > 28 days old; and studies not in English.

\section{Search strategy}

We searched the literature published before 4 March 2019. No restrictions were imposed in terms of publication language, time, or status. We did not restrict publication date because we aimed to maximize the number of potential studies included. Electronic database searches used both free text queries and Medical Subject Headings (MeSH) terms. Using the MEDLINE, EMBASE, Web of Science, and Cochrane Library databases, we performed a systematic review of publications reporting $\mathrm{CHD}$ diagnosed with Echo in newborns with cardiac murmurs. Moreover, a grey literature search strategy was adapted, as appropriate, other than the major databases in order for data retrieval as many as possible with the study objectives. The goal of the search strategy was to retrieve all relevant articles related to the topic. For management of the searched literature, Endnote version X7 (Thomson Reuters, New York, NY) was used. The details of the search strategies used are provided as an appendix to this review (Additional file 1).

\section{Study selection}

Study selection was independently decided by two reviewers based on the predefined inclusion and exclusion criteria. Discrepancies were resolved by discussion among the reviewers. Any remaining disagreements were 
referred to a third author to achieve a consensus. In addition, study selection included two screening levels. The two reviewers independently screened the titles and abstracts of identified studies. Subsequently, the investigators retrieved the articles identified by the reviewers for full-text review. Thereafter, the reviewers assessed the reports to ensure that they met the inclusion criteria.

\section{Identification of relevant studies}

Figure 1 shows a flow diagram of how the relevant studies were identified. In total, 825 studies were identified by searching four databases and manually searching relevant bibliographies: In total, 786 studies were identified by searching 4 databases and manually searching relevant bibliographies as follows: 182 studies from MEDLINE, 128 from EMBASE, 100 from Cochrane Library,
376 from Web of Science, and 39 by manual searching. We excluded 156 duplicate studies and 610 studies that did not satisfy the inclusion criteria and/or met the exclusion criteria. After reviewing the full texts of the remaining 20 studies, eight studies were further excluded for the following reasons: participants included symptomatic newborns $(n=4)$ or preterm infants $(n=4)$ (Additional file 2). Thus, a total of 12 studies were included in the analysis [24-26, 28-36].

\section{Data extraction and screening methods}

Two reviewers independently identified potential studies and extracted detailed information from each article according to the recommendations of the Cochrane Handbook for Systematic Reviews of

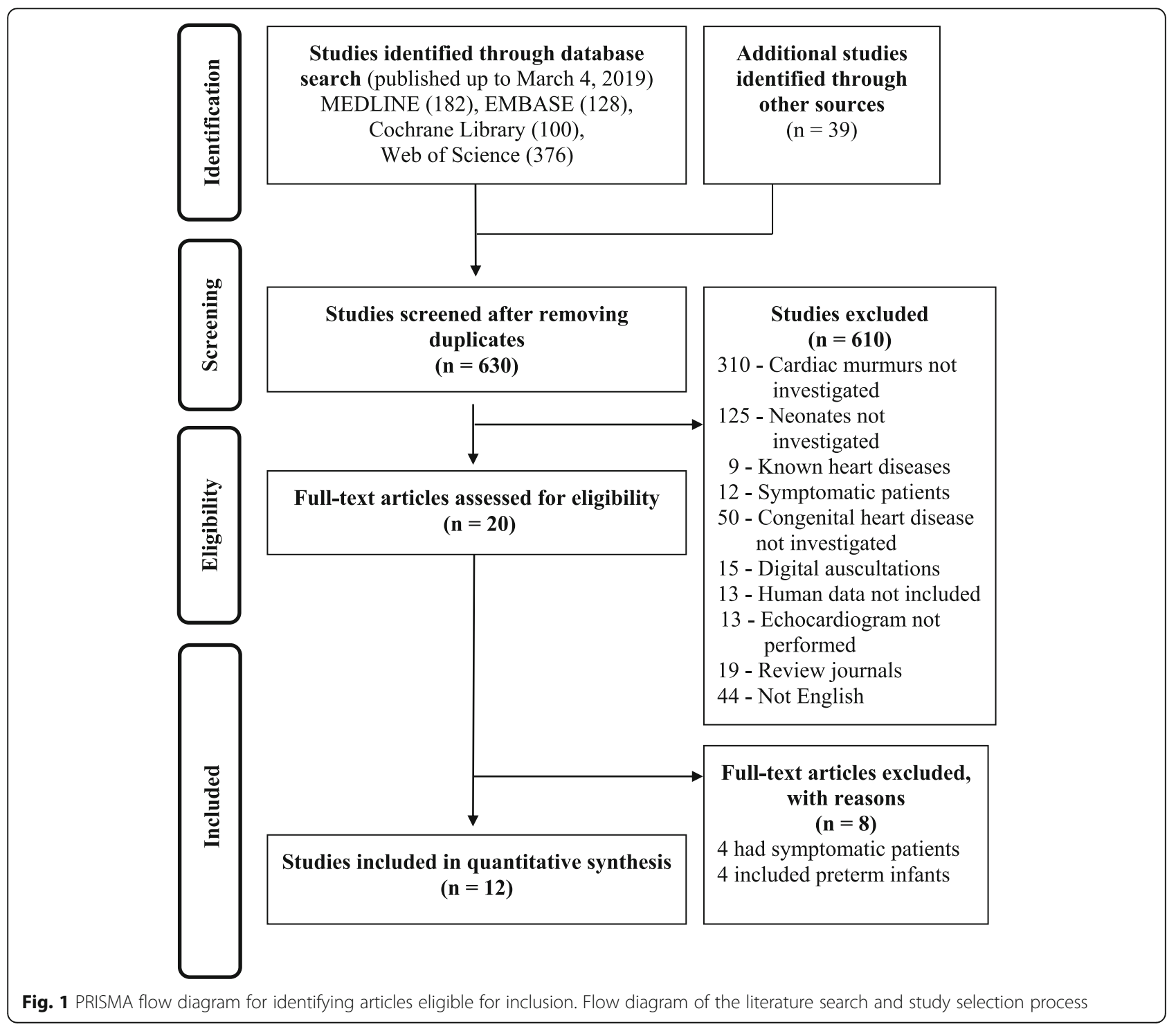


Interventions Version 6 [37] and the PRISMA screening process [27] (Fig. 1).

The extracted data included indexing information about the article, such as the first author's name, year of publication, and country where the study was performed; study design; clinical setting; total number of participants; patient demographic information, such as sex and mean age; and findings from initial screenings for CHD, additional examinations for CHD, and echocardiograms. For ANCM, the measured outcome varied among studies. The following designations of abnormal cardiac sounds were extracted from the studies: benign murmurs, possible pathologic murmurs, and pathologic murmurs.

\section{Quality assessment}

The methodological quality of the included studies was assessed according to the Study Quality Assessment Tools developed by the National Institutes of Health (NIH) [38]. Two reviewers (S.A.Y. and H.J.C.) scored the studies according to these scales. If the ratings differed, then the authors discussed the article in an effort to reach a consensus.

\section{Results}

\section{Study characteristics}

Characteristics of the studies and the subjects are summarized in Table 1. Of the included studies, six were cohort studies $[25,26,28,29,32,33]$, four were crosssectional studies $[24,30,31,34]$, and two were case reports [35, 36]. A total of 1928 subjects were included in the 12 studies. Clinical settings varied and included nurseries, neonatal intensive care units (NICU), and outpatient clinics.

\section{Synthesis of screening for CHD}

Table 2 shows a summary of the initial and additional cardiac evaluations performed in each study. In most of the studies, the first cardiac evaluations were performed within five days of birth by pediatricians. Since 2012, screening newborns using a pulse oximeter has become standard practice [26, 32, 34, 35]. Except in one study [32], additional assessments using Echo were performed by a pediatric cardiologist during the neonatal period before discharge (an additional assessment using Echo performed in an outpatient setting was excluded [30]). Additionally, some studies used chest x-ray [24], electrocardiogram $[24,26,30,35]$, and four-limb blood pressure $[26,35]$ to further evaluate cardiac murmurs.

\section{Incidence of ANCM and CHD according to the type of cardiac murmurs}

From the eight studies, the incidence of ANCM ranged from 0.6 to $8.6 \%$, and the CHD incidence among infants with ANCM ranged from 2.6 to $74.1 \%$ (Table 3). We evaluated CHD incidence according to cardiac murmur designation in three studies [24-26]. The incidence of $\mathrm{CHD}$ in newborns with pathologic murmurs was higher than in those with benign or possible pathologic murmurs.

\section{Synthesis of echocardiographic outcomes}

Of the 1928 asymptomatic newborns with cardiac murmurs who underwent Echo and were included in our study, 719 (37.3\%) were diagnosed as having CHD. We classified CHD into four categories according to the anatomical region that produced the murmur: shunt lesions, right side heart lesions, left side heart lesions, and connection lesions (Table 4). Among the newborns with CHD, 56.5\% had shunt lesions. The most common CHD was ventricular septal defect (VSD).

\section{Severity of CHD in newborns with ANCM}

Three studies [26, 33, 34] stratified CHD severity according to the level of interventions required (Table 5). Of the 267 newborns in the three studies, nine (3.4\%) had critical CHD necessitating immediate intervention, such as heart surgery or cardiac catheterization, before hospital discharge.

\section{Results of study quality assessment}

Table 6 shows the results of each study's quality assessment. Two reviewers rated each study according to the study design using the Study Quality Assessment Tools developed by the NIH. Scoring system was as $2=$ yes; $1=$ unclear or not applicable; $0=$ no. A total score was graded as excellent (75-100\%), good (50-75\%), fair (25$50 \%)$ and poor (0-25\%). Among six cohort studies, three $[25,26,32]$ scored excellent while the rest $[28,29,33]$ were good. Three of four cross-sectional studies [24, 30, $34]$ were graded as excellent and one was good. Two case reports $[35,36]$ scored excellent.

\section{Discussion}

This is the first systematic review to evaluate the usefulness of Echo for the diagnosis of CHD among newborns with ANCM. We found that approximately $1 \%$ of the cohort from the included studies had ANCM, and more than one third were diagnosed as having CHD using Echo. Moreover, the incidence of cardiac murmurs was influenced by the frequency and time of examination as well as the experience and skills of the physicians. Initial screening for murmurs was performed before the first discharge in most of the studies. In the study by Rein et al., cardiac auscultations were performed daily [29]. The level of expertise of the physicians who performed the initial assessments varied (i.e., pediatric residents to 


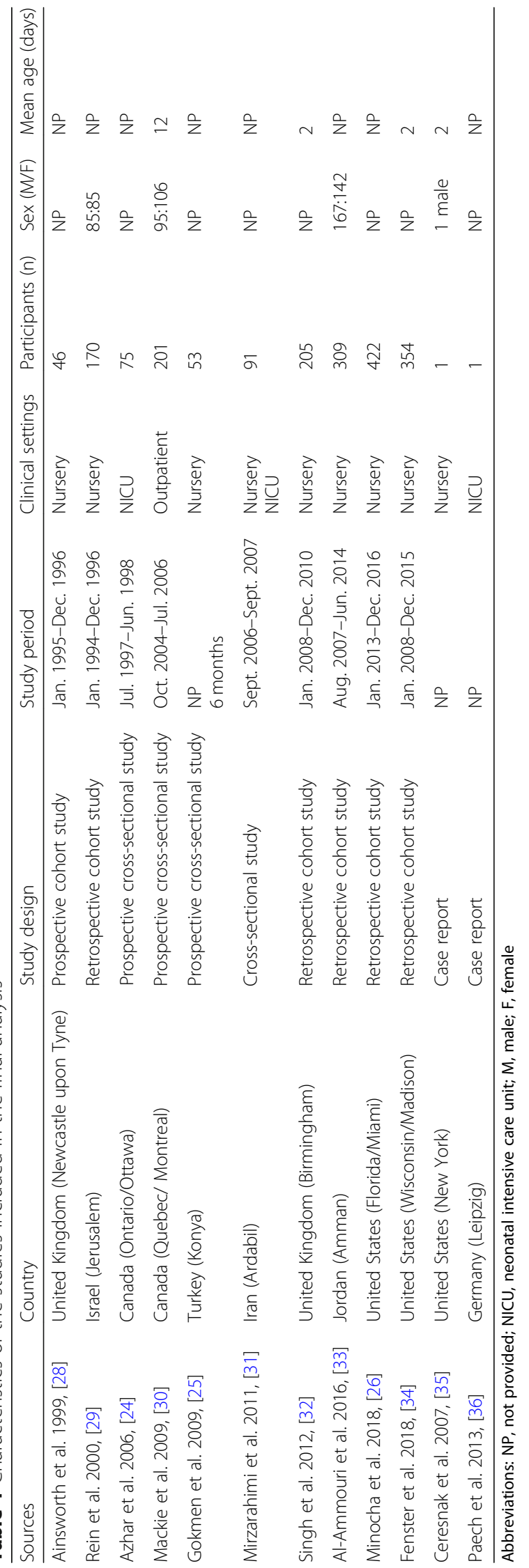


Table 2 Summary of the initial screening and additional assessment for cardiac murmurs in asymptomatic newborns

\begin{tabular}{|c|c|c|c|c|c|}
\hline \multirow[b]{2}{*}{ Sources } & \multicolumn{3}{|l|}{ Initial screening } & \multicolumn{2}{|l|}{ Additional assessment } \\
\hline & Time & Frequency & Physicians & Time & Physicians \\
\hline Ainsworth et al. 1999, [28] & $\leq 48 \mathrm{~h}$ & NP & Neonatologist/obstetrician & Within $24 \mathrm{~h}$ after the murmur was heard & $\begin{array}{l}\text { Pediatric } \\
\text { cardiologist }\end{array}$ \\
\hline Rein et al. 2000, [29] & $\leq 5 \mathrm{~d}$ & Daily & Neonatologist & Median $4 \mathrm{~h}$ from request for echocardiogram & $\begin{array}{l}\text { Pediatric } \\
\text { cardiologist }\end{array}$ \\
\hline Azhar et al. 2006, [24] & $1-28 d$ & NP & Neonatologist & NP & $\begin{array}{l}\text { Pediatric } \\
\text { cardiologist }\end{array}$ \\
\hline Mackie et al. 2009, [30] & NP & NP & NP & $2-31$ days & $\begin{array}{l}\text { Pediatric } \\
\text { cardiologist }\end{array}$ \\
\hline Gokmen et al. 2009, [25] & NP & NP & Pediatrician & $\begin{array}{l}\text { On the day of or the day after the initial } \\
\text { screening }\end{array}$ & $\begin{array}{l}\text { Pediatric } \\
\text { cardiologist }\end{array}$ \\
\hline Mirzarahimi et al. 2011, [31] & $\leq 24 \mathrm{~h}$ & NP & Pediatrician & NP & $\begin{array}{l}\text { Pediatric } \\
\text { cardiologist }\end{array}$ \\
\hline Singh et al. 2012, [32] & NP & NP & $\begin{array}{l}\text { Middle grade neonatal } \\
\text { trainee }\end{array}$ & Median age 2 days & Neonatologist \\
\hline Al-Ammouri et al. 2016, [33] & $\leq 48 \mathrm{~h}$ & NP & Pediatric resident & $\leq 48 \mathrm{~h}$ & $\begin{array}{l}\text { Pediatric } \\
\text { cardiologist }\end{array}$ \\
\hline Minocha et al. 2018, [26] & $\leq 72 \mathrm{~h}$ & NP & NP & $\leq 72 \mathrm{~h}$ & $\begin{array}{l}\text { Pediatric } \\
\text { cardiologist }\end{array}$ \\
\hline Fenster et al. 2018, [34] & $\leq 4 \mathrm{~d}$ & NP & NP & Median age 2 days & $\begin{array}{l}\text { Pediatric } \\
\text { cardiologist }\end{array}$ \\
\hline Ceresnak et al. 2007, [35] & 2nd day of life & NP & NP & $\begin{array}{l}\text { On the day of or the following day after } \\
\text { the initial screening }\end{array}$ & $\begin{array}{l}\text { Pediatric } \\
\text { cardiologist }\end{array}$ \\
\hline Paech et al. 2013, [36] & NP & NP & NP & $\begin{array}{l}\text { On the day of or the following day after } \\
\text { the initial screening }\end{array}$ & NP \\
\hline
\end{tabular}

Abbreviations: NP, not provided

Table 3 Asymptomatic newborns with cardiac murmurs and congenital heart disease diagnosed with echocardiogram

\begin{tabular}{llll}
\hline Sources & $\begin{array}{l}\text { Number of newborns } \\
\text { during the study period }\end{array}$ & Number of newborns with murmurs (\%) & Number of newborns with murmurs with CHD (\%) \\
\hline Ainsworth et al. [28] & 7204 & $46(0.6)$ & $25(54.3)$ \\
Rein et al. [29] & 20,323 & $170(0.8)$ & $110(64.7)$ \\
Azhar et al. [24] & - & 75 & $55(73.3)$ \\
& & Innocent, 10 & $7(70.0)$ \\
& & Possibly pathological, 9 & $5(55.6)$ \\
Mackie et al. [30] & - & Pathological, 56 & $43(76.8)$ \\
Gokmen et al. [25] & 618 & 201 & $113(56.2)$ \\
& & $53(8.6)$ & $19(35.8)$ \\
Mirzarahimi et al. [31] & 2928 & Innocent, 41 & $11(26.8)$ \\
Singh et al. [32] & 21,957 & Pathological, 12 & 8 (66.7) \\
Al-Ammouri et al. [33] & 22,215 & $91(3.1)$ & $32(35.2)$ \\
Minocha et al. [26] & 25,128 & $205(0.9)$ & $152(74.1)$ \\
& & $309(1.4)$ & $68(22.0)$ \\
Fenster et al. [34] & 26,573 & $422(1.7)$ & $11(2.6)$
\end{tabular}


Table 4 Echocardiographic outcomes of newborns with cardiac murmur $(N=1928)^{a}$

\begin{tabular}{|c|c|c|c|}
\hline \multicolumn{2}{|c|}{ Echocardiographic outcomes } & \multirow{2}{*}{$\frac{n(\%)}{282(14.6)}$} & \multirow{2}{*}{$\frac{\text { References }}{[24,26,28-34]}$} \\
\hline Shunt lesions & Ventricular septal defect & & \\
\hline & Atrial septal defect ( $\geq 4 \mathrm{~mm}$ ) & $55(2.8)$ & {$[24,28-33]$} \\
\hline & Ventricular septal defect + Atrial septal defect & $15(0.8)$ & {$[29,31,33]$} \\
\hline & Atrioventricular septal defect & $4(0.2)$ & {$[24,26,32,34]$} \\
\hline & Significant patent ductus arteriosus & $50(2.6)$ & {$[24,30,34]$} \\
\hline \multirow[t]{3}{*}{ Right side heart lesions } & Pulmonary valve anomaly (dysplasia, stenosis) & $37(1.9)$ & {$[24,26,28-34]$} \\
\hline & Tetralogy of Fallot & $15(0.8)$ & {$[26,28-30,32-34]$} \\
\hline & Ebstein anomaly & $2(0.1)$ & {$[29,34]$} \\
\hline \multirow[t]{5}{*}{ Left side heart lesions } & Cor triatriatum & $1(0.1)$ & [29] \\
\hline & Mitral valve regurgitation & $4(0.2)$ & {$[29,32]$} \\
\hline & Aortic valve anomaly (bicuspid valve, stenosis) & $18(0.9)$ & {$[24,28-30,33,34,36]$} \\
\hline & Hypoplastic left heart syndrome & $3(0.2)$ & {$[29,33]$} \\
\hline & Coarctation of the aorta & $9(0.5)$ & {$[28-30,32,34]$} \\
\hline \multirow[t]{3}{*}{ Connection lesions } & Transposition of great arteries & $6(0.3)$ & {$[24,29,31]$} \\
\hline & Partial anomalous pulmonary venous return & $4(0.2)$ & {$[26,30,34]$} \\
\hline & Anomalous origin of the right pulmonary artery from the ascending aorta & $1(0.1)$ & [29] \\
\hline \multirow[t]{2}{*}{ Others } & Coronary artery fistula & $1(0.1)$ & [35] \\
\hline & Ventricular hypertrophy & $5(0.3)$ & [31] \\
\hline \multicolumn{2}{|c|}{ Normal or physiologic variant } & $1211(62.8)$ & {$[24-26,28-34]$} \\
\hline \multicolumn{2}{|l|}{ Not described } & $343(17.8)$ & {$[24,25,32,34]$} \\
\hline
\end{tabular}

${ }^{a}$ The number of diagnoses exceeds the number of patients with congenital heart disease because some patients had multiple diagnoses

neonatologists). Initial cardiac evaluations for newborns consisted of cardiac auscultation, obtaining family history of $\mathrm{CHD}$, and screening with a pulse oximeter, the last of which was added in 2012. Primary cardiac murmur evaluations and Echo were performed simultaneously, except in one outpatient clinic-based study [30]. Regardless of low diagnostic potential, electrocardiogram, chest $\mathrm{x}$-ray, and four-limb blood pressure measurements were performed as additional assessment methods for cardiac murmurs in four studies [24, 26, 30, 35]. In this systematic review, Echo was performed by pediatric cardiologists in all but one study, in which Echo was performed by a neonatologist [32].

CHD incidence varied greatly among the studies, which could be attributable to CHD prevalence variations between different countries [4-6]. Information on antenatal ultrasound screening for CHD according to the country where the study was conducted was not

Table 5 Severity of congenital heart disease in asymptomatic newborns with cardiac murmur

\begin{tabular}{|c|c|c|}
\hline Sources & Classification of CHD severity & CHD number (\%) \\
\hline \multirow[t]{4}{*}{ Al-Ammouri et al. [33] } & Total CHD & 68 \\
\hline & Critical: hypoplastic left heart syndrome, aortic stenosis & $4(5.9)$ \\
\hline & $\begin{array}{l}\text { Significant: CHD proved to be symptomatic and/or eventually required intervention } \\
\text { during infancy or childhood }\end{array}$ & $18(26.5)$ \\
\hline & Others & $46(67.6)$ \\
\hline \multirow[t]{4}{*}{ Minocha et al. [26] } & Total CHD & 188 \\
\hline & Critical: CHD requiring immediate intervention & $2(1.1)$ \\
\hline & Major: $\mathrm{CHD}$ requiring intervention within 12 months of life & $26(13.8)$ \\
\hline & Minor: CHD expected to resolve spontaneously or unlikely to require intervention & $160(85.1)$ \\
\hline \multirow[t]{3}{*}{ Fenster et al. [34] } & Total CHD & 11 \\
\hline & CHD triggered a change in management before hospital discharge & $3(27.3)$ \\
\hline & CHD necessitating outpatient cardiology follow-up & $8(72.7)$ \\
\hline
\end{tabular}


Table 6 Appraisal of study quality

\begin{tabular}{|c|c|c|c|c|c|c|c|c|c|c|c|c|c|c|c|}
\hline \multicolumn{16}{|c|}{ Observational cohort studies (assessed with NIH tool) ${ }^{a}$} \\
\hline & Q1 & Q2 & Q3 & Q4 & Q5 & Q6 & Q7 & Q8 & Q9 & Q10 & Q11 & Q12 & Q13 & Q14 & Score ${ }^{b}$ \\
\hline Ainsworth et al. [28] & 2 & 2 & 2 & 2 & 1 & 2 & 2 & 0 & 0 & 0 & 2 & 0 & 2 & 1 & $18 / 28$ \\
\hline Rein et al. [29] & 2 & 2 & 2 & 2 & 1 & 2 & 2 & 0 & 0 & 2 & 0 & 0 & 2 & 1 & $18 / 28$ \\
\hline Gokmen et al. [25] & 2 & 0 & 2 & 2 & 1 & 2 & 2 & 2 & 2 & 2 & 0 & 2 & 2 & 1 & $22 / 28$ \\
\hline Singh et al. [32] & 2 & 2 & 2 & 2 & 1 & 2 & 2 & 2 & 2 & 2 & 0 & 1 & 2 & 1 & $23 / 28$ \\
\hline Al-Ammouri et al. [33] & 2 & 2 & 2 & 2 & 1 & 2 & 2 & 0 & 0 & 0 & 2 & 1 & 2 & 1 & $19 / 28$ \\
\hline Minocha et al. [26] & 2 & 2 & 2 & 2 & 1 & 2 & 2 & 2 & 2 & 1 & 2 & 1 & 2 & 1 & $24 / 28$ \\
\hline \multicolumn{16}{|c|}{ Cross-sectional studies (assessed with $\mathrm{NIH}$ tool) } \\
\hline Azhar et al. [24] & 2 & 2 & 2 & 2 & 1 & 2 & 2 & 2 & 2 & 2 & 0 & 2 & 2 & 1 & $24 / 28$ \\
\hline Mackie et al. [30] & 2 & 2 & 2 & 2 & 1 & 2 & 2 & 2 & 2 & 0 & 2 & 2 & 2 & 1 & $24 / 28$ \\
\hline Mirzarahimi et al. [31] & 2 & 2 & 2 & 0 & 1 & 2 & 2 & 0 & 0 & 0 & 0 & 1 & 2 & 1 & $15 / 28$ \\
\hline Fenster et al. [34] & 2 & 2 & 2 & 2 & 1 & 2 & 2 & 1 & 2 & 1 & 2 & 1 & 2 & 1 & $23 / 28$ \\
\hline \multicolumn{16}{|c|}{ Case reports (assessed with $\mathrm{NIH}$ tool) } \\
\hline & Q1 & Q2 & Q3 & Q4 & Q5 & Q6 & Q7 & Q8 & Q9 & Score & & & & & \\
\hline Ceresnak et al. [35] & 2 & 2 & 2 & 0 & 2 & 2 & 2 & 1 & 2 & $15 / 18$ & & & & & \\
\hline Paech et al. [36] & 2 & 2 & 2 & 0 & 2 & 2 & 2 & 1 & 2 & $15 / 18$ & & & & & \\
\hline
\end{tabular}

${ }^{a}$ Two assessors rated each study. In the instance of a dispute, a third assessor was involved and a consensus was reached by majority

${ }^{b}$ Scoring system: 2 =yes; 1 = unclear or not applicable; $0=$ no.

Abbreviations: NIH, National Institutes of Health

available. Only one study reported that the lower CHD incidence in their study compared to previous studies could be attributed to active prenatal detection of most of the major and critical cases of CHD [26]. The incidence of CHD among full term newborns with ANCM found in this systematic review (37.3\%) was much higher than the updated prevalence of $\mathrm{CHD}$ at birth. Among the subtypes of CHD, shunt lesions such as VSD, atrial septal defect (ASD), and patent ductus arteriosus (PDA) were most frequently observed, which is consistent with the worldwide prevalence of CHD at birth $[4,6]$.

With regard to the severity of CHD in newborns [39], three studies classified CHD severity as follows: mild, moderate, and severe [26, 33, 34]. Of the 267 newborns with CHD in the three studies, $3.4 \%$ were diagnosed as having severe CHD and thus required immediate interventions, such as heart surgery or interventional catheterization, before hospital discharge. In this systematic review, even though acyanotic severe heart diseases, such as large VSD, ASD, and PDA as well as critical aortic or pulmonary stenosis, were not included, $2.5 \%$ had severe CHD. The majority of the newborns had moderate CHD requiring outpatient cardiology follow-up [24, 26, 28-36].

Cardiac murmurs heard in the first few days of life are mostly associated with physiologic variants, such as peripheral pulmonary stenosis, and typically disappear within 3 to 6 months of life. Cardiac murmurs due to CHD are more easily auscultated after the decrease in pulmonary resistance that occurs after several weeks of life $[40,41]$. Nevertheless, we observed a high CHD incidence in the included studies that performed initial cardiac evaluations within five days of life. Generally, pathologic murmurs that are described as louder than 2/6 in intensity, diastolic, and pansystolic and are associated with rubs, clicks, or gallops are relevant to CHD [42, 43]; however, we observed that CHD includes not only pathologic murmurs but also innocent murmurs, such as ANCM. While pathologic murmurs are associated with a higher CHD incidence, newborns with innocent murmurs showed a CHD incidence rate of $0.6-70 \%$.

Among the included studies, only one study described an algorithm in which Echo was performed in all newborns with pathologic murmurs regardless of symptoms and in some newborns with innocent murmurs present $>48 \mathrm{~h}$ after birth [32]. Cardiac murmur is the most common reason for referral to a cardiologist and shows a relatively higher Echo diagnostic yield than other indications, such as palpitation or chest pain. Moreover, abnormal echocardiographic findings are most frequently observed within the first year of life among pediatric patients with cardiac murmurs [44]. Although Echo is the gold standard for the diagnosis of CHD and is easily accessible in developed countries, there is no consensus on whether to use Echo in newborns with ANCM. Nevertheless, a few physicians have performed Echo in full term newborns with ANCM [14, 34]. Although there are issues with cost-effectiveness and technical accessibility, Echo is currently widely used, even in 
the NICU, by neonatologists [45-48]. New approaches for the utilization of Echo in newborns with ANCM are warranted.

Early diagnosis and timely management of $\mathrm{CHD}$ in newborns are critical to improve clinical outcomes [5, 49]. With the increase in artificial fertilization and preterm births, CHD incidence is expected to increase in the future [50]. A thorough cardiac evaluation with careful auscultation before hospital discharge should be performed to screen for CHD. Because accuracy of the assessment of pathologic murmurs varies among physicians $[24,30,51]$, a stepwise approach to evaluating cardiac murmurs is required. Considering the difficulties in distinguishing pathologic murmurs from innocent murmurs in newborns, the use of Echo in newborns with ANCM is recommended to prevent further cardiac complications. If access to Echo is limited, early referral to a pediatric cardiologist may be another option.

All studies included in this review were observational studies. A meta-analysis was impossible because of the study designs. However, this systematic review applied a comprehensive and structured search strategy to four different databases. Two reviewers independently performed quality assessment, thereby reducing selection and publication bias.

\section{Conclusion}

Recently, Echo is being widely used for heart anatomy imaging and cardiac function evaluation in newborns with normal cardiac structure; thus, guidelines for the use of Echo in newborns with ANCM are warranted. In this systematic review, cardiac murmurs were the most common abnormal findings after physical examinations in newborns and we found that $>37 \%$ of newborns with ANCM had moderate to severe CHD diagnosed using Echo. Thus, Echo is a useful non-invasive tool for the detection of cardiac problems in newborns with cardiac murmurs and is an easy diagnostic procedure for CHD. Our study suggests that utilization of Echo in newborns with ANCM would be helpful in early CHD detection, which could in turn improve clinical outcomes.

\section{Supplementary information}

Supplementary information accompanies this paper at https://doi.org/10. 1186/s12887-020-02212-8

Additional file 1. Detailed search strategy and returned number of articles.

Additional file 2. Excluded studies with reasons for exclusion.

\section{Abbreviations}

CHD: Congenital heart disease; echo: Echocardiogram; ANCM: Asymptomatic non-syndromic cardiac murmurs; PRISMA: Preferred reporting items for systematic reviews and meta-analysis; MeSH: Medical Subject Headings; $\mathrm{NIH}$ : National Institutes of Health; NICU: Neonatal intensive care unit; VSD: Ventricular septal defect; ASD: Atrial septal defect; PDA: Patent ductus arteriosus; MedRIC: Medical Research Information Center; NRF: National Research Foundation of Korea

\section{Acknowledgments}

This research was supported by the Medical Research Information Center (MedRIC) through the National Research Foundation of Korea (NRF), which is funded by the Ministry of Science and ICT of the Korean Government (NRF No. 2018R1A6A6040880).

\section{Authors' contributions}

SAY conceptualized and designed the study, performed the initial analyses, and drafted the initial manuscript. WHH conceptualized and designed the study and reviewed and revised the manuscript. SYA and HJC collected data and reviewed and revised the manuscript. SAY and WHH coordinated and supervised data collection and critically reviewed the manuscript. All authors approved the final manuscript as submitted.

Funding

Not applicable.

\section{Availability of data and materials}

The data that support the findings of this study are available from the corresponding author (hong.medric@gmail.com) upon reasonable request.

Ethics approval and consent to participate

Not applicable.

\section{Consent for publication}

Not applicable.

\section{Competing interests}

The authors declare that they have no competing interests.

\section{Author details}

${ }^{1}$ Department of Pediatrics, Chungbuk National University Hospital, (28644) 1 Chungdae-ro, Seowon-gu, Cheongju-si, Chungcheongbuk-do, South Korea. ${ }^{2}$ College of Medicine, Medical Research Information Center, Chungbuk National University, (28644) 1 Chungdae-ro, Seowon-gu, Cheongju-si, Chungcheongbuk-do, South Korea. ${ }^{3}$ Department of Pathology, Inje University Busan Paik Hospital, (47392) 75 Bokji-ro, Busanjin-gu, Busan, South Korea.

Received: 3 November 2019 Accepted: 16 June 2020

Published online: 30 June 2020

\section{References}

1. Oster ME, Lee KA, Honein MA, Riehle-Colarusso T, Shin M, Correa A Temporal trends in survival among infants with critical congenital heart defects. Pediatrics. 2013;131:e1502-8.

2. Sankar MJ, Natarajan CK, Das RR, Agarwal R, Chandrasekaran A, Paul VK. When do newborns die? A systematic review of timing of overall and cause-specific neonatal deaths in developing countries. J Perinatol. 2016; 36(Suppl 1):S1-11.

3. Bairoliya N, Fink G. Causes of death and infant mortality rates among fullterm births in the United States between 2010 and 2012: an observational study. PLoS Med. 2018;15:e1002531.

4. van der Linde D, Konings EE, Slager MA, Witsenburg M, Helbing WA, Takkenberg JJ, et al. Birth prevalence of congenital heart disease worldwide: a systematic review and meta-analysis. J Am Coll Cardiol. 2011;58:2241-7.

5. Triedman JK, Newburger JW. Trends in congenital heart disease: the next decade. Circulation. 2016;133:2716-33.

6. Liu Y, Chen S, Zuhlke L, Black GC, Choy MK, Li N, et al. Global birth prevalence of congenital heart defects 1970-2017: updated systematic review and meta-analysis of 260 studies. Int J Epidemiol. 2019;48:455-63.

7. Marelli AJ, Mackie AS, lonescu-Ittu R, Rahme E, Pilote L. Congenital heart disease in the general population: changing prevalence and age distribution. Circulation. 2007;115:163-72.

8. Wren C, Richmond S, Donaldson L. Presentation of congenital heart disease in infancy: implications for routine examination. Arch Dis Child Fetal Neonatal Ed. 1999;80:F49-53.

9. Hill GD, Block JR, Tanem JB, Frommelt MA. Disparities in the prenatal detection of critical congenital heart disease. Prenat Diagn. 2015;35:859-63. 
10. van Velzen CL, Clur SA, Rijlaarsdam ME, Bax CJ, Pajkrt E, Heymans MW, et al. Prenatal detection of congenital heart disease--results of a national screening programme. BJOG. 2016;123:400-7.

11. Dorfman AT, Marino BS, Wernovsky G, Tabbutt S, Ravishankar C, Godinez RI, et al. Critical heart disease in the neonate: presentation and outcome at a tertiary care center. Pediatr Crit Care Med. 2008;9:193-202.

12. Kondo M, Ohishi A, Baba T, Fujita T, lijima S. Can echocardiographic screening in the early days of life detect critical congenital heart disease among apparently healthy newborns? BMC Pediatr. 2018;18:359.

13. Fillipps DJ, Bucciarelli RL. Cardiac evaluation of the newborn. Pediatr Clin N Am. 2015;62:471-89.

14. Shenvi A, Kapur J, Rasiah SV. Management of asymptomatic cardiac murmurs in term neonates. Pediatr Cardiol. 2013:34:1438-46.

15. Rice MJ, McDonald RW, Reller MD, Sahn DJ. Pediatric echocardiography: current role and a review of technical advances. J Pediatr. 1996:128:1-14.

16. Frommelt MA, Frommelt PC. Advances in echocardiographic diagnostic modalities for the pediatrician. Pediatr Clin N Am. 1999:46:427-39 xi.

17. Simpson JM, Miller O. Three-dimensional echocardiography in congenital heart disease. Arch Cardiovasc Dis. 2011;104:45-56.

18. Chitra N, Vijayalakshmi IB. Fetal echocardiography for early detection of congenital heart diseases. J Echocardiogr. 2017;15:13-7.

19. Driscoll D, Allen HD, Atkins DL, Brenner J, Dunnigan A, Franklin W, et al. Guidelines for evaluation and management of common congenital cardiac problems in infants, children, and adolescents. A statement for healthcare professionals from the committee on congenital cardiac defects of the council on cardiovascular disease in the young, American Heart Association. Circulation. 1994;90:2180-8

20. Hiremath $\mathrm{G}$, Kamat $\mathrm{D}$. When to call the cardiologist: treatment approaches to neonatal heart murmur. Pediatr Ann. 2013:42:329-33.

21. Writing Group for Echocardiography in Outpatient Pediatric Cardiology, Campbell RM, Douglas PS, Eidem BW, Lai WW, Lopez L, et al. ACC/AAP/AHA ASE/HRS/SCAI/SCCT/SCMR/SOPE 2014 appropriate use criteria for initial transthoracic echocardiography in outpatient pediatric cardiology: a report of the American College of Cardiology Appropriate Use Criteria Task Force, American Academy of Pediatrics, American Heart Association, American Society of Echocardiography, Heart Rhythm Society, Society for Cardiovascular Angiography and Interventions, Society of Cardiovascular Computed Tomography, Society for Cardiovascular Magnetic Resonance, and Society of Pediatric Echocardiography. J Am Soc Echocardiogr. 2014;27:1247-66.

22. Naik RJ, Shah NC. Teenage heart murmurs. Pediatr Clin N Am. 2014;61:1-16.

23. Begic E, Begic Z. Accidental heart murmurs. Med Arch. 2017;71:284-7.

24. Azhar AS, Habib HS. Accuracy of the initial evaluation of heart murmurs in neonates: do we need an echocardiogram? Pediatr Cardiol. 2006;27:234-7.

25. Gokmen Z, Tunaoglu FS, Kula S, Ergenekon E, Ozkiraz S, Olgunturk R. Comparison of initial evaluation of neonatal heart murmurs by pediatrician and pediatric cardiologist. J Matern Fetal Neonatal Med. 2009;22:1086-91.

26. Minocha P, Agarwal A, Jivani N, Swaminathan S. Evaluation of neonates with suspected congenital heart disease: a new cost-effective algorithm. Clin Pediatr (Phila). 2018:57:1541-8.

27. Liberati A, Altman DG, Tetzlaff J, Mulrow C, Gotzsche PC, loannidis JP, et al The PRISMA statement for reporting systematic reviews and meta-analyses of studies that evaluate healthcare interventions: explanation and elaboration. BMJ. 2009:339:b2700.

28. Ainsworth S, Wyllie JP, Wren C. Prevalence and clinical significance of cardiac murmurs in neonates. Arch Dis Child Fetal Neonatal Ed. 1999:80:F43-5.

29. Rein AJ, Omokhodion SI, Nir A. Significance of a cardiac murmur as the sole clinical sign in the newborn. Clin Pediatr (Phila). 2000;39:511-20.

30. Mackie AS, Jutras LC, Dancea AB, Rohlicek CV, Platt R, Beland MJ. Can cardiologists distinguish innocent from pathologic murmurs in neonates? J Pediatr. 2009:154:50-4.e1.

31. Mirzarahimi M, Saadati H, Doustkami H, Alipoor R, Isazadehfar K, Enteshari A. Heart murmur in neonates: how often is it caused by congenital heart disease? Iran J Pediatr. 2011;21:103-6.

32. Singh A, Desai T, Miller P, Rasiah SV. Benefits of predischarge echocardiography service for postnatal heart murmurs. Acta Paediatr. 2012; 101:e333-6.

33. Al-Ammouri I, Ayoub F, Dababneh R. Is pre-discharge echocardiography indicated for asymptomatic neonates with a heart murmur? A retrospective analysis. Cardiol Young. 2016;26:1056-9.

34. Fenster ME, Hokanson JS. Heart murmurs and echocardiography findings in the normal newborn nursery. Congenit Heart Dis. 2018;13:771-5.
35. Ceresnak S, Gray RG, Altmann K, Chen JM, Glickstein JS, Hellenbrand WE. Coronary artery fistulas: a review of the literature and presentation of two cases of coronary fistulas with drainage into the left atrium. Congenit Heart Dis. 2007;2:208-13.

36. Paech C, Pfeil N, Wagner R, Kostelka M, Weidenbach M. Aortico-left ventricular tunnel bypassing congenital critical aortic stenosis. Echocardiography. 2013;30:E344-5.

37. Higgins JPT, Thomas J, Chandler J, Cumpston M, Li T, Page MJ, Welch VA, editors. Cochrane handbook for systematic reviews of interventions. 2nd ed. Chichester (UK): John Wiley \& Sons; 2019.

38. Tools SQA. National Heart, Lung, and Blood Institute, Bethseda. MD. https:// www.nhlbi.nih.gov/health-topics/study-quality-assessment-tools.

39. Hoffman JIE, Kaplan S. The incidence of congenital heart disease. J Am Coll Cardiol. 2002;39:1890-900.

40. Chatelain P, Oberhansli I, Friedli B. Physiological pulmonary branch stenosis in newborns: 2D-echocardiographic and Doppler characteristics and follow up. Eur J Pediatr. 1993;152:559-63.

41. Arlettaz R, Archer N, Wilkinson AR. Natural history of innocent heart murmurs in newborn babies: controlled echocardiographic study. Arch Dis Child Fetal Neonatal Ed. 1998:78:F166-70.

42. Pelech AN. Evaluation of the pediatric patient with a cardiac murmur. Pediatr Clin N Am. 1999:46:167-88.

43. Frank JE, Jacobe KM. Evaluation and management of heart murmurs in children. Am Fam Physician. 2011:84:793-800.

44. Lang SM, Bolin E, Hardy S, Tang X, Collins RT 2nd. Diagnostic yield of outpatient pediatric echocardiograms: impact of indications and specialty. Pediatr Cardiol. 2017;38:162-9.

45. Singh Y. Echocardiographic evaluation of hemodynamics in neonates and children. Front Pediatr. 2017:5:201.

46. Chamsi-Pasha MA, Sengupta PP, Zoghbi WA. Handheld echocardiography: current state and future perspectives. Circulation. 2017;136:2178-88.

47. Singh $Y$, Katheria A, Tissot C. Functional echocardiography in the neonatal intensive care unit. Indian Pediatr. 2018:55:417-24.

48. Simpson JM, van den Bosch A. Educational series in congenital heart disease: three-dimensional echocardiography in congenital heart disease. Echo Res Pract. 2019;6:R75-86.

49. Jenkins KJ, Botto LD, Correa A, Foster E, Kupiec JK, Marino BS, et al. Public health approach to improve outcomes for congenital heart disease across the life span. J Am Heart Assoc. 2019;8:e009450.

50. Giorgione V, Parazzini F, Fesslova V, Cipriani S, Candiani M, Inversetti A, et al. Congenital heart defects in IVF/ICSI pregnancy: systematic review and metaanalysis. Ultrasound Obstet Gynecol. 2018;51:33-42.

51. Karatza AA, Fouzas S, Tzifas S, Mermiga A, Dimitriou G, Mantagos S. Accuracy of cardiac auscultation in asymptomatic neonates with heart murmurs: comparison between pediatric trainees and neonatologists. Pediatr Cardiol. 2011:32:473-7.

\section{Publisher's Note}

Springer Nature remains neutral with regard to jurisdictional claims in published maps and institutional affiliations.

Ready to submit your research? Choose BMC and benefit from:

- fast, convenient online submission

- thorough peer review by experienced researchers in your field

- rapid publication on acceptance

- support for research data, including large and complex data types

- gold Open Access which fosters wider collaboration and increased citations

- maximum visibility for your research: over $100 \mathrm{M}$ website views per year

At BMC, research is always in progress.

Learn more biomedcentral.com/submissions 